\title{
Inheritance Path of Traditional Festival Culture from the Perspective of Ghost Festival in Luju Town
}

\author{
Jiayi Lu, Jianghua Luo \\ ${ }^{1,2}$ Key Research Institute of Humanities and Social Sciences at University, Center for Studies Education and \\ Psychology of Ethnic Minorities in Southwestern China, Southwest University, Beibei, Chongqing 400715
}

\begin{abstract}
By participating in a series of activities of Ghost Festival on July 15th, teenagers naturally accept the ethical education of filial piety and benevolence. However, under the background of urbanization of villages, teenagers are away from their local families, and family controlling power and influence have been weakened. All these problems become prominent increasingly. As a result, the cultural connotations of Ghost Festival have been misinterpreted, and its survival and inheritance are facing a crisis. Therefore, we must grasp the essence in the inheritance of traditional cultures and make families and schools play their roles on the basis of combination of modern lives.
\end{abstract}

Keywords: Ghost Festival, local villages, inheritance of culture, teenagers

Fund Project: Comparative Study of the Status Quo of Educational Development of Cross-border Ethnic Groups in Southwestern China - major project of humanities and social science key research base which belongs to the Ministry of Education. (Project Number: 11JJD880028)

About the Author: Lu Jiayi, student of Southwestern Ethnic Education and Psychology Research Center of Southwest University, Luo Jianghua, associate professor of Southwestern Ethnic Education and Psychology Research Center of Southwest University, PhD, Chongqing 400715.

Chinese Ghost Festival refers to the festival of ghost worship. In China there are more than one Chinese Ghost Festival festivals. Some of them are celebrated widely, such as Qingming festival, Hungry ghost festival (also known as July 15 Ghost Festival), Woolies festival and so on The research direction of this paper focuses on July 15 Ghost Festival.

Study in academia on July 15th Ghost Festival (Buddhism calls it Obon Festival, Taoism calls it Hungry ghost festival started from research works about ideology and culture, festival custom in tang dynasty. Represented by the Buddhist temple culture history in Han and tang dynasties of Zhang Gong, when he talked about Buddhist festivals, he deeply analyzed the origin of Ghost Festival and the process of nationalization. He pointed out that Hungry ghost festival absorbed the keynote of clan delivery from Buddhism. Buddhist Obon and Hungry ghost festival are celebrated on the same day, which is a marvel in medieval culture Since last century, articles have some parts about the origin, activities and occasions of Hungry Ghost Festival, the fusion of Confucianism, Buddhism and Taoism reflected by it from following works, namely,Taoism in the tang dynasty in the dojo Settings by Wang Yongping, formation and features of folk Buddhism by Li Silong, the origin and evolution of Chinese festival by Mou Yuangui, and Chinese ghost festival and Yin and Yang five elements: from the Qing Ming festival and the hungry ghost festival by Gao Hongxing.

But related research mainly focuses on the following two aspects, research and discussion on the naturalization and secularization of Ghost Festival. As for the study on nationalization, it reveals the process of its nationalization to a certain extent. However, it does not deeply and comprehensively study the social ideology and culture popular among Confucianism, Buddhism and Taoism reflected by the Obon, Hungry Ghost Festival, and Chinese Ghost Festival. It does not make it clear about the cultural connotation from this phenomenon and the function of the important issues, and not pay enough attention to the inheritance of present status. Therefore, the author prepares to study the cultural connotation, educational function and the present inheritance on July 15 Ghost Festival. Besides, it analyzes the case of Luju town, Jiangchuan County in Yunnan province. This study selected 300 teenagers aged from 10 to 30 as investigated objects (including 125 teenagers from at school, 175 teenagers from society) and carried on the questionnaire survey and participatory observation and in-depth interviews on their working situation away from town, the cognition and participation of Ghost Festival by the use of mass media, and so on. 


\section{Ceremony of Receiving, Serving and Sending the Ghost on July 15th}

It was said that July 15th was the officers' birthday. The hell amnesty ghosts allowed them to return to earth. Some ghost went home if they had someone received them, and some would wander about if they did not have. Ghosts asked for money and clothes from their family for their living when they came back to hell [4]. Therefore, people sacrifice food, burning incense, pray for the dead and good life in the middle of July. Gradually, the custom takes shape to worship ghost in the middle of July.

Ceremony is a symbol communication system established by a kind of culture. It consists of a series of serialized and stereotyped words and behavior [5]. The whole ceremony process of Ghost Festival on July 15th has its stable structure, including receiving, serving and sending the ghost. According to the tradition from Luju town, every family shall receive ghost that night when ancestor came back home on July 12th fro their festival. Housewives would prepare rice wine, tea and meals, and then bring ancestors home from the grave to purlin shrine after reading text vocalese and burning incense. This represents a combination of ancestors and gods. After that, it people shall serve the ghost after three days with sincere heart. They prepare three meals a day in purlin with respect for ancestors, burn incense and kowtow bowing.

The most exquisite part is sending ancestors away on July 15th. People pack baggage at noon, which is loading baggage with clothing shoes and hats, silver paper money according to the ancestors of generational names. They prepare all the sacrificed food such as steamed cake, meat, fruit and vegetables, wine, water, tea, etc. They take it to the front of the shrine first for altar burning and kowtow bowing, and then send ancestors out of the door by kowtowing with pouring wine at the same time. Sending ghost is the climax of Ghost Festival ceremony. The place usually is chosen in the big unobstructed crossing at the village, so that it is easy for ancestors to walk on the road. The main process is painting circle, bowing to the four directions, altar, burning baggage, and sacrifice. They paint the circle with stove ash according to the amount of baggage and put one baggage into one circle. After putting the baggage, housewives lit incense and worship to north and south, east and west, praying for all the gods to bless ancestor. After worship, they will stick the incense in the outer ring oven according to dual number. Then, they would burn the baggage according to their seniority in the family. This process is called coating burning. People burn the baggage and call their ancestors at the same time. They call ancestors to fetch their stuff for the living in the hell. They read the eulogy and pray good life without disaster for ancestors. The works they read are often externalized and the content of it is closely fit to life. They need to make sure that every baggage is burned totally so that ancestors can receive full money and clothes. After burning the baggage, people kowtow to ancestors' grave, which generally is three times. At last, they place sacrifice food around the stove circle and let ancestors bring them back to enjoy.

Second, The cultural connotation and educational value of Ghost Festival on July 15th

One, Ghost Festival has the function of paying respect to ancestors, praying luckiness and avoid evil, educating future generations

\section{The Cultural Connotation and Educational Value of Halloween on July 15th} (1) Halloween Has the Function of Paying Respect to Ancestors, Praying Luckiness and Avoid Evil, Educating Future Generations

The Book of Rites said that every person, don't rush to the ritual, there are five classics, don't focus on offering. Based on July 15th Ghost Festival worshiped by ancestors, undoubtedly, the theme is definitely ancestor worship. Confucius said that paying respect to ancestors, people will have the common pursuit to the country. Through celebrating Ghost Festival, people show their grief and respect to ancestors, who embodies the Chinese paying respect to ancestors and give back kindness to them. It also shows people are gratitude to their ancestors and the faith in their clan. At the same time, people also stick to education about their family tradition and ancestors' stories during this Ghost Festival ceremony in memory of their ancestors. It tends to educate the future generations with the example of ancestors.

In addition, through a series of activities such as receiving, serving and sending ancestors, Ghost Festival on July 15th builds an invisible bridge between people and the ancestors, and realizes the combination between profane and sacred entities. With the dialogue with the ancestors, people speak out their wishes for happy family and escape of disasters, and pray for good harvest and good animals in the coming year. Zhang Qiya thinks that rural ceremony is mainly out of a psychological activity that they want ancestral identity for their behavior and protection. It is actually a continuation of history and an objective psychological demand. This demand is still significant to some degree in today's society [6]. Praying for luckiness and escape of disasters is the basic power in the ceremony of Ghost Festival. In the face of the hardships of social life, through the blessing of ancestors, people can adapt their attitude and get comfort from it. Besides, worship also contains the long-cherished wish to pursue a better life. 
(2) Ghost Festival Combines the Ethics Thought of Filial Piety and Benevolence from Confucianism, Buddhism, and Taoism

July 15 Ghost Festival is the festival celebrated by Confucianism, Buddhism, and Taoism. The basic for the three religions on the same day is that they all advocate filial piety [7]. The ancients said that dutiful son prays for ancestors. There are three ways to show it. Support their parents if they have. Mourn their parents if they don't have. Pray for their parents if they died. Dutiful son should do all of the three. So it is easily to conclude that dutiful son does not only refer to the parents, but the first is showing respect to their ancestors. Local people in Luju town express their filial piety in the form of ancestor worship on Ghost Festival. At the same time, they also take over all the wandering soul wild ghost out of their fear. Investigation found that people tend to prepare additional baggage for wild ghosts when they packing baggage for ancestors with actual amount. Some researchers think that it is of extreme of Confucian ethics theory. With the Filial piety to mothers and to other people, it shows the consistence with the universal love of Confucian [8].

At the victor Turner's study, ceremony takes the role of building and copying social relationship. It is a symbol of the social order, and makes its members to comply with the corresponding social order [9]. In Chinese tradition, value on loss of life, respect for ancestor, and worship is the concrete expression of filial piety in Chinese core culture. The symbolic meaning of filial piety from ancestor worship has been firmly down into the Chinese society culture. Ancestor worship on Ghost Festival is not only a way to express filial piety, it also contains the obligations of secular ethics. These are the code of ethics and code of conduct that every member of the society needs to abide by. If a man doesn't worship ancestors, it will be considered as unfilial act, and criticism will ensue.

\section{(3) Sacrifice on Ghost Festival is a Kind of Education in Life}

Sacrifice on Ghost Festival adopts participation as a mode of education. It is a kind of typical life education. It integrates classroom, teaching materials and teachers into the life, so that each person can be naturally involved and get the morality education in Ghost Festival activities. Teenagers take actual ceremony activities, and learn festival abundant symbol system through the field observation. For example, they prepare sacrificed offerings with elders prepare. During this, elders tell stories of the hard work, thrifty of their ancestors. Learners can feel the real infiltration among them, and gain the subtle enlightenment. Then they would internalize their ancestral spirit into part of their own. Besides, teaching and learning are put in a solemn, grand and mysterious atmosphere. The emotional arousal and communication go naturally. learners are unconsciously influenced by the enlightenment, in which can get twice the result with half the effort with lifetime influence and actions consciously or unconsciously reveals its lasting impact in the future .

\section{(1) The loss of youth cultural successor}

\section{Current Crisis of Cultural Heritage in Ghost Festival}

With urbanization of villages, the villagers' land is expropriated. After lost ground, the villagers pour into cities to find jobs. With the investigation of three villages of 100 households, it is found that the proportion of migrant workers accounts for $62.3 \%$, including Zhangying village up to $70.2 \%$ of migrant workers. According to the village head of Zhangying village, the age of people who work for other cities ranges from 16 to 60 , and most people are around the age of 17 to 45 . There are about 10 households that the whole family are out of village for work, and even includes teenagers who drop out of school to join the migrant workers.

With the growing number of migrant youth for work, they are away from the original village life, and then lose the opportunity to celebrate Ghost Festival. After dropping out of school, these teenagers seldom do farming at home. Instead, they go out for work, which makes the traditional festival culture disconnected between generations. Even for some students who stay in the village, with the concept strongly impacted by modern education, many of them think that ancestor worship is not important, and instead the most important thing is to study and have a good result and future. Besides, as old housewives, the leader of the ancestor worship ceremony died, young housewives who are not familiar with the Ghost Festival process, cannot not undertake the ceremony down which is mastered skillfully by the last generation. So they do not have the ability to take this job by themselves. For example, they don't draw focal circle before burning baggage when they send ancestors alone. They do not read any eulogy during this process. This leads to a loss of Ghost Festival culture. The ceremony has been simplified, the core elements have been shed, and the core of Ghost Festival has been hollowed out. All of these make the original festival culture lose their authenticity.

\section{(2) The Influence and Control of Culture Teachers from Progenitor and Parents is Weakening}

Traditional rural society is very isolated. People are born and died in the same village. The normal life is to die in the same town. It is a familiar society. This familiar is the result coming from countless small friction [10]. The culture inheritance and transmission of Ghost Festival is conducted in this familiar society. The traditional model belongs to the type of the pre-figurative culture [11]. That is the elders are an example for the 
younger generation to learn. The elder's way of life, values, and emotional attitude are told orally to the younger generation. This top-down way of inheriting brands deeply in the growth of children.

In recent 3 years, with the rise in the number of rural migrant youth, the static closed system of the traditional family gradually becomes the breakthrough. Family members are no longer altogether, and geographical isolation lead to a drop in contact daily life. The size of the family is also shrinking, which increasingly emerges as a central tendency. Grandchildren are no longer living with my grandparents. The traditional big family through the contact between the generations is abated, and most of the children have limited interaction between the elders and themselves. Teenagers' cognition on traditional festival culture is no longer from the story of the past told by parents, and teenagers are gradually away from traditional life world. As the decreasing of intergenerational interaction, the control and influence from parents is weakening. Cultural inheritance seems to be out of its original chain and track, which leads to the disconnection between teenagers and traditional festival culture.

\section{(3) The Mass Media Accelerates the Decline of Traditional Festival Culture Inheritance}

With the development of cultural tourist area, the urbanization and modernization level is increasing day by day. Under this background, mass media is developing fast. Firstly, television media is dominant in the market. Luju town in 2011 achieved universal coverage of digital TV with family ownership of $93.2 \%$, and the digital TV can receive 70 multiple channels. Among 300 investigated teenagers, its television exposure rate was $100 \%$. Secondly, the mobile phone ownership keeps rising. The mobile phone ownership among students was $47 \%$, while the social ownership of teenagers was $92.8 \%$. And the proportion has the trend to expand. Thirdly, the Internet is developing rapidly. In September 2013, every village in Luju town has been implemented broadband Internet, and more and more families bought computers. Internet cafe is also increasing. There were 8 Internet cafes in three natural villages which were surveyed, and 6 in township streets.

The influx of mass media brings more complicated multicultural, and the traditional ideas and values of teenager are shocked by them. At the same time with the experience of urban life, they contact with all kinds of people who are different in aspects such as food and clothing live line, language and culture, value and so on. Because young people are often more susceptible to the effects, they quickly accept and practice the new way of life, values, and then lack the interest in traditional culture. Through the interviews with seven teenagers who returned back home, they think Ghost Festival ceremony is the feudal superstition and inheritance is backward culture with resistance psychologically. In this view, the connotation of Ghost Festival is misinterpreted. With the reduction of recognition, the consciousness of teenagers to inherit gradually fades away. This will inevitably affect the culture heritage and development of Ghost Festival festival.

\section{Explore the Path of Inheritance in the Traditional Festival Culture (1) Grasp the Cultural Essence of Ghost Festival. Pay Attention to the Combination with Modern Life}

In 1976, Richard Dawkins presents a gene selection theory. It emphasizes the choice is about replicators, and replication can be stable for a long time to save its own structure, to adapt to the environment changes. The survival of the fittest survival is stable one. According to Dawkins, cultural genes, human spiritual culture replicators, loads the culture life, and inherit a kind of culture. It needs to analyze it, and to grasp the essence of [12]. Some of the surface layer form of Ghost Festival has changed. For example, some villagers no longer receive ancestors from graveyard, instead they do it symbolically. They also no longer make baggage, but buy them directly from the market. Despite all of thee, the core essence is still the ancestor worship. They conduct a series of activities for the ethical education of filial piety and benevolence while they recall and honor ancestors. With grasping the culture essence of Ghost Festival, and safeguarding its uniqueness and sanctity, we can better cope with the issues of shallow and shell on festival.

Second, the value orientation of cultural heritage should be present and future. The inheritance of traditional culture should be connected to the reality of the cultural survival. That is to say, it needs to excavate the life significance in the reality and the future from the traditional local culture for teenagers [13]. For example, much worship contains the respect for ancestors. In the face of learning and employment pressure, the youth can use the hardworking story of preaching ancestors to encourage them to persevere in the face of difficulties and remain positive and enterprising. Therefore, nowadays with the rapid change of local village, traditional festival culture needs to reorganize and apply with the real life during its inheritance.

\section{(2) Reestablish the Status of Family in the Traditional Festival Culture}

With the deep influence of mass media, especially the rapid development of Internet, the younger generation quickly adapt to the changes with their unique keen intuition, grasp more updated science and technology, and catch up with their parents in some aspects such as information technology, the network shopping and entertainment, etc. These facts indicate that society increasingly shows the characteristics of cofigurative culture as Mead said. The co-figurative culture indicates the emergence of new cultural inheritance 
pattern, that is the younger generation pass the cultural to the elders. Therefore, parents need to change the traditional ideas. They no longer see themselves as an authority, no longer strongly require children to participate in the festival sacrifice. Instead, they communicate with children as an equal, let them know the significance and value of ancestor worship. They perceive children's thought and conduct festival culture education in the way they like.

Moreover, with the improvement of exoteric extent in some rural village, family can't pass on culture alone. It must form effective linkage with school and mass media, and fully participate in a pluralistic society life. It plays its unique role in such aspects as value orientation, judgment, identify and choose. It gives effective supplement and correction to the shortcomings of modern society. It guides teenagers to recognize the fundamental value of the traditional festival culture, and rebuilds the status of cultural heritage in traditional festivals [14].

\section{(3) Play an Important Role of School in the Traditional Festival Culture}

As the local village is changing and family control is weakening, which leads to the limit for community and family in Ghost Festival cultural inheritance. With its systematic, normative, organizational characteristics, school plays a very important role in the traditional festival inheritance. Schools have professionals to write teaching materials and special personnel to teach. It collects traditional festival into the school curriculum, which is not only more standardized, more scientific, but also guarantees the basic class.

In addition, the traditional festival is closely connected with people's production and living, and has outstanding practical features. Ghost Festival sacrifice itself is a kind of life education. Through the ceremony performance, teenagers naturally get enlightenment. Therefore, in order to carry out the education on the traditional festival culture such as Ghost Festival, it should adopt the mode of exploring the participation and experience in traditional festivals, rather than a method of classroom infusion [15]. For example, it let students personally involve in the festival. Through the observation and imitation, it let students taste the culture connotation of festive. By creating conditions to carry out activities such as class meetings with the theme of traditional holiday, and investigation of traditional festival, it let teenagers enjoy themselves and actively participate in. Meanwhile, teachers must be good at discovering the education value from ceremony, and grasp the chance to consciously strengthen the traditional virtue of festivals and custom in activities. By teaching through lively activities, it let teenagers consciously become the master of culture inheritance in traditional festival.

\section{References}

[1] Chinese Academy of Social Sciences [M]. China's Social Science Documentation Publishing House, 2007(5).

[2] Luo Qirong, Yang Renxuan, Chinese Traditional Festivals [M] Beijing: Popular Science Press, 1986.

[3] Zhang Gong, Cultural History of Buddhist Temples during Han and Tang Dynasties [M]. Beijing: China Social Science Press, 1997.

[4] Chen Jiujin, Lu Lianrong, Chinese Festivals and Their Origins [M]. Shanghai: Shanghai Science and Technology Education Press, 1989.

[5] (British) Fiona Bowie, The Anthropology of Religion: An Introduction [M] translated by Jin Ze and He Qimin, Chinese People's University Press, 2004

[6] Zhang Qiya, Social Cohesion of Folk Rituals [J]. Journal of Guizhou University (Social Science Edition), 2009(5).

[7] Zhang Jiyu, Loyalty, Filial Piety and the Immortals [J], Chinese Taoism, 2003 (1).

[8] Yang simin, On the Formation, Development and Cultural Value of Hungry Ghost Festival [J]. Guizhou Literature and History Series, 1991(2).

[9] (British) Vistor Turner, Ritual Process: Structure and Anti-structure [M]. Translated by Huang Jianbo and Liu Boyun, Chinese People's University Press, 2006

[10] Fei Xiaotong, Local China [M]. People's Press, 2008 (10)

[11] (American) Margaret Meade, Culture and Commitment [M], Shijiazhuang, Hebei People's Publishing House, 1987 (4).

[12] (British) Richard Dawkins, the Selfish Gene [M]. translated by Lu Yunniu, etc. Jilin People’s Press, 1998.

[14] Zhang Xianglong, Crisis of Chinese Traditional Culture [EB/OL]. Ancient Chinese Literature Forum. http:www.guoxue.com/ws/index2.asp.2004-01-12.

[15] Lu Desheng Looking at the Chinese Traditional Culture Inheritance from the Change of Tibetan Opera "Qie Suo" [C]. the 2007 National Doctoral Forum (Education) 